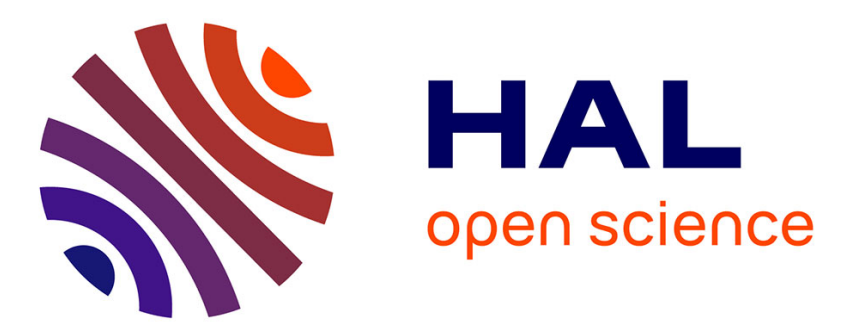

\title{
Bonding of aluminium matrix composites for application in the transport industry
}

\author{
A. Ureña, J.M. Gómez de Salazar
}

\section{To cite this version:}

A. Ureña, J.M. Gómez de Salazar. Bonding of aluminium matrix composites for application in the transport industry. Journal de Physique IV Proceedings, 1993, 03 (C7), pp.C7-1037-C7-1042. 10.1051/jp4:19937161 . jpa-00251785

\section{HAL Id: jpa-00251785 https://hal.science/jpa-00251785}

Submitted on 1 Jan 1993

HAL is a multi-disciplinary open access archive for the deposit and dissemination of scientific research documents, whether they are published or not. The documents may come from teaching and research institutions in France or abroad, or from public or private research centers.
L'archive ouverte pluridisciplinaire HAL, est destinée au dépôt et à la diffusion de documents scientifiques de niveau recherche, publiés ou non, émanant des établissements d'enseignement et de recherche français ou étrangers, des laboratoires publics ou privés. 


\title{
Bonding of aluminium matrix composites for application in the transport industry
}

\author{
A. UREÑA and J.M. GÓMEZ DE SALAZAR \\ Dpto. Ciencia de los Materiales e Ingeniería Metalúrgica, Facultad de Ciencias Químicas, Universidad \\ Complutense de Madrid, 28040 Madrid, Spain
}

\begin{abstract}
.
A discontinuously reinforced $\mathrm{MMC}$ containing $12 \mathrm{vol} \% \mathrm{SiC}$ particles in an Al-Cu-Mg alloy (AA 2124) matrix has been diffusion bonded. Thick interlayers of different superplastic aluminium alloys (Al-Li 8090 and Al-Cu SUPRAL) were used to reduce the bonding pressure and ensure complete surface contact. Microstructural studies shown higher continuity in joints bonded with 8090 interlayer than with other alloys. Precipitation of rich-copper intermetallic was detected, after bonding, in the interlayer because diffusion of $\mathrm{Cu}$ from 2124 matrix. Results suggest that $\mathrm{Li}$ contained in the interlayer favours the partial disruption of the aluminium oxide film, making easier the solid state bonding.
\end{abstract}

\section{INTRODUCTION.}

Discontinuously reinforced aluminium (DRA) composites composed of high strength aluminium alloys reinforced with silicon carbide particles $\left(\mathrm{SiC}_{\mathrm{p}}\right)$ or whiskers $\left(\mathrm{SiC}_{\mathrm{w}}\right)$ are gaining widespread acceptance because their relatively low cost compared to unidirectional continuous fibre-reinforced metal matrix composites (1). Besides, their combination of properties and fabricability make them attractive candidates for structural components in the transport industry, which require high strength /density ratio. So, DRA composites have been developed for weight-critical applications in the aerospace industry and also present potential uses in automotive applications (suspension members, engine blocks, cam shaft, etc) (2).

One of the problems which avoid the extensive application of DRA composites in structures is its joining. For this reason, it is necessary to develop techniques for obtaining strong homogeneous between DRAs and heterogeneous joints with other structural metallic materials (aluminium, titanium, steels, etc). Solid state bonding avoids the microstructural degradation associated with conventional welding processes (change in array of fibres and deterioration of them) (3).

However, diffusion bonding of aluminium alloys is difficult because the protective oxide film $\left(\mathrm{Al}_{2} \mathrm{O}_{3}\right)$ present on the metal surface, which prevents the formation of the necessary metallic contact to obtain a solid state union (4). It makes necessary to use different interlayer coatings or foils $(\mathrm{Cu}, \mathrm{Ag}$ or $\mathrm{Zn}$ ) to facilitate the bond formation (5). Diffusion bonding of DRAs also shows the previous difficulty. Besides, the use of interlayers (metallic foils) produces a change in the number and distribution of the reinforce particles in the bond regions, which conditions the mechanical properties of the joint (6). 
In the present investigation, in order to select the optimum metallic interlayer to bond an Al-Cu 2124 alloy reinforced with silicon carbide particles; two different interlayers have been used: i) an aluminium-lithium alloy (AA8090) and ii) an aluminium-copper superplastic alloy (SUPRAL 100).

Both interlayers were selected because their similar composition to the composite matrix, but with the presence of some alloying elements $(\mathrm{Li}, \mathrm{Cu})$ which could facilitate the solid state bonding. Besides, the increasing use of both alloys in the aerospace applications makes interesting the study of their diffusion bonding with DRA composites.

Present paper shows the results of these investigations, specially those related with the microstructural changes occurred in the bond interfaces and the effects of the bonding parameters and postbonding heat treatments on them.

\section{EXPERIMENTAL PROCEDURE.}

The parent material used was a discontinuous reinforced metal matrix composite containing 12 vol \% silicon carbide particles in Al-Cu-Mg alloy (AA2124). It was received in the form of a $6 \mathrm{~mm}$ thick sheet with the standard T6 treatment of the AA2124. Interlayers used were an 8090 Al-Li alloy and a SUPRAL $100 \mathrm{Al}-\mathrm{Cu}$ alloy, both with superplastic properties. They were applied in the form of foils with thickness in the range of $50-150 \mu \mathrm{m}$. Chemical compositions of parent composite matrix and both interlayer alloys are shown in Table I.

\begin{tabular}{|c|c|c|c|c|c|c|c|c|c|c|c|c|}
\hline ALLOY & $\mathrm{Cu}$ & $L_{i}$ & $\mathrm{rg}$ & $m$ & si & $\mathrm{Fe}$ & $z_{r}$ & cr & $\mathrm{Ti}$ & $\mathrm{zn}$ & sn & $\mathrm{Na}$ \\
\hline AA2124 & 4.4 & - & 1.5 & 0.5 & 0.2 & 0.3 & - & 0.10 & 0.10 & 0.25 & - & - \\
\hline AA 8090 & 1.2 & 2.4 & 0.6 & - & 0.03 & 0.07 & 0.14 & - & - & - & - & $<0.001$ \\
\hline $\begin{array}{c}\text { SUPRAL } \\
100\end{array}$ & 5.9 & - & 0.04 & 0.07 & 0.08 & 0.16 & - & $<0.01$ & $<0.01$ & $<0.02$ & $<0.01$ & - \\
\hline
\end{tabular}

The sheet surfaces were ground down to 1200 grade emery paper. Specimens were chemically cleaned with a commercial deoxidant for aluminium alloys and degreased in an ultrasonic bath with acetone. Interlayer foils were prepared in the same way than DRA composite.

Diffusion bonds were carried out at temperatures in the range of $470-520^{\circ} \mathrm{C}$, bonding pressures of 3 and $6 \mathrm{MPa}$, and times of 60 minutes. Every bonding trials were carried out in a vacuum atmosphere of $2 \cdot 10^{-4}$ Torr. The influence of the solution heat treatment (SHT) at $500^{\circ} \mathrm{C}$ during $4-8 \mathrm{~h}$, followed by cold water quenching (Q) and, occasionally, artificial ageing at $191{ }^{\circ} \mathrm{C}$ during 16 hours, were also studied.

Microstructural studies of bonding interfaces were carried out using scanning electron microscopy (SEM). Composition changes originated in the bond regions were determined by energy dispersive spectrometry (EDS), although microhardness measurement were also applied as an indirect method to determinate the diffusion of lithium when AA8090 interlayer was used.

\section{RESULTS.}

\subsection{4-SiC $\mathrm{MMC} / \mathrm{AA8090}$ diffusion joints.}

Diffusion bond microstructure of MMC joints with 8090 interlayer is very dependent on bonding temperature and pressure. Bonding at $500{ }^{\circ} \mathrm{C}$ and $6 \mathrm{MPa}$ during $1 \mathrm{~h}$, the interlayer foil undergoes an heterogeneous deformation reducing its thickness from $150 \mu \mathrm{m}$ to values lower than $80 \mu \mathrm{m}$ (Fig. 1). The high plasticity of the Al-Li alloy at the bonding conditions origins the plastic flow of the foil, which even disappeared in some zones (Fig. 2). At these bonding conditions, the bulk deformation induced in the specimen was higher than $50 \%$. 


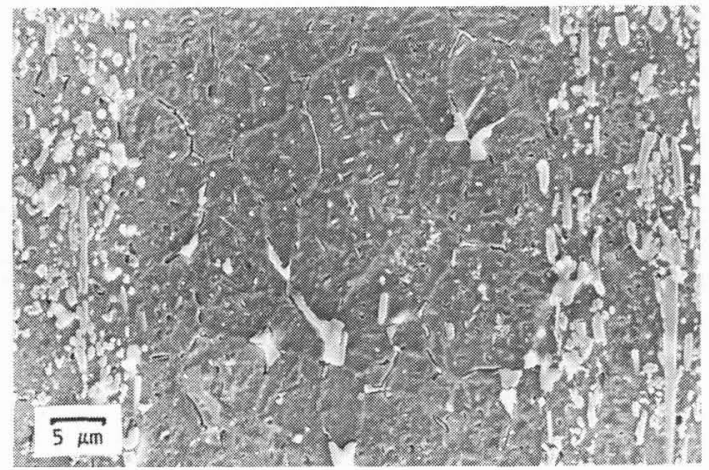

Fig. 1. DRA composite joint with 8090 interlayer $\left(500^{\circ} \mathrm{C}, 6 \mathrm{MPa}\right)$.

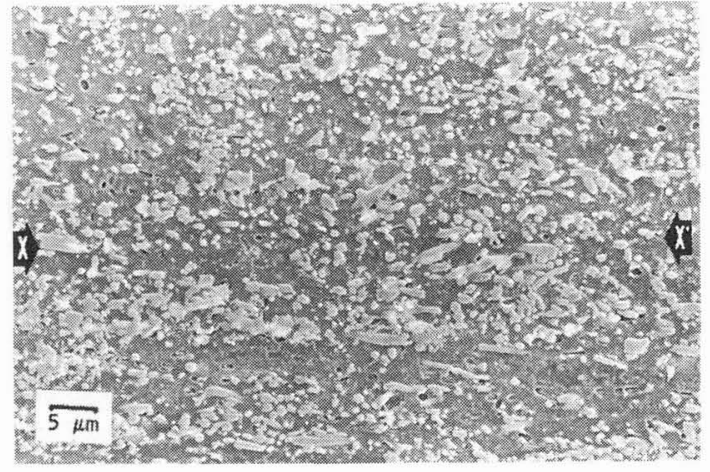

Fig. 2. Zone of complete elimination of interlayer by plastic flow $\left(\mathrm{X}-\mathrm{X}^{\prime}\right)$.

The study of the interlayer microstructure shows the massive precipitation of rich-copper phases $\left(\mathrm{CuAl}_{2}\right.$ phase) inside it (Fig 3a-b). The post bonding heat treatment applied $(\mathrm{SHt}+\mathrm{Q})$ provided the almost complete solubilitation of them, and reveals the recrystallization and grain growth occurred across the original bong interfaces (Fig. 4). In these points, original interfaces are not distinguished and SiC particles appear inside the new grains. This effect is more evident in those zones were interlayer was eliminated
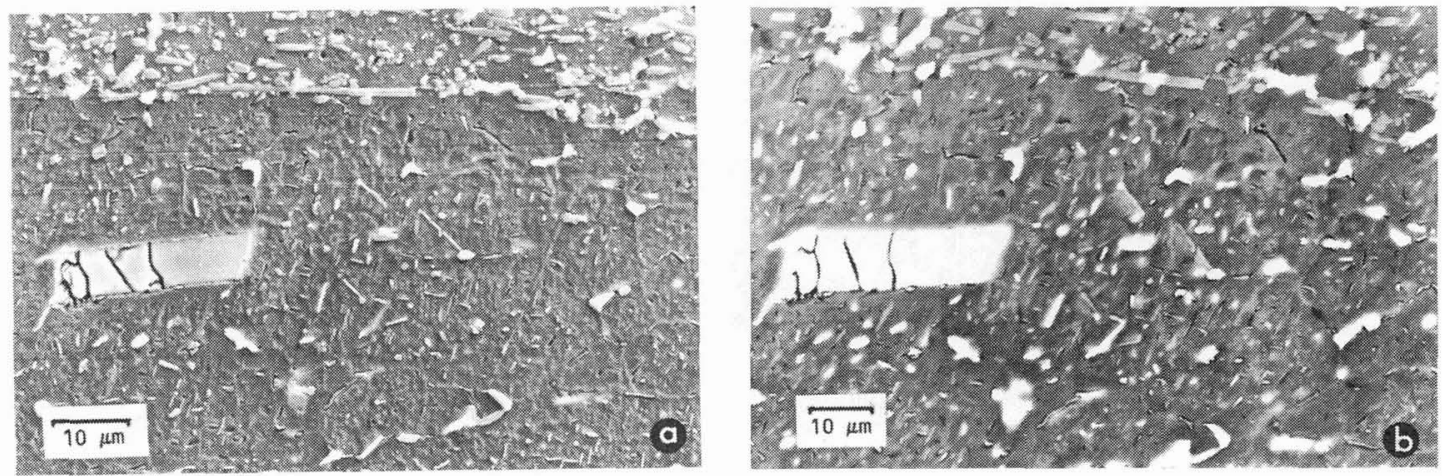

Fig. 3. Precipitation of rich-Cu phases in 8090 interlayer. a) SE; b) BSE images.

by plastic flow (Fig. 5). The SiC particle distribution was uniform in these zones, although some banding and clustering were observed on a microscopic scale.

Decreasing the bonding pressure down to $3 \mathrm{MPa}$ is possible to delimitate the MMC bulk deformation under $25 \%$ without loss of high integrity microstructure in the bond interface. However, under these conditions, the interlayer was homogeneously deformed down to $120 \mu \mathrm{m}$ thick (Fig. 6). Microhardness measurements in this specimen after SHT + Q+ageing show a softening of the interlayer regions close to the bond interface and an increase of the MMC hardness in the vicinity of both bond lines (Fig. 7).

Bonding at $480{ }^{\circ} \mathrm{C}$ with pressures of $6 \mathrm{MPa}$ is possible to obtain microstructure similar than figure 3 , but reducing the bulk deformation to values lower than $10 \%$. However, for lower bonding temperatures $(<$ $470{ }^{\circ} \mathrm{C}$ ), interfaces with residual porosity are obtained and some evidences of interfacial oxidation were detected (Fig. 8). In spite of it, massive precipitation of rich-Cu phases inside the interlayer was again observed. 


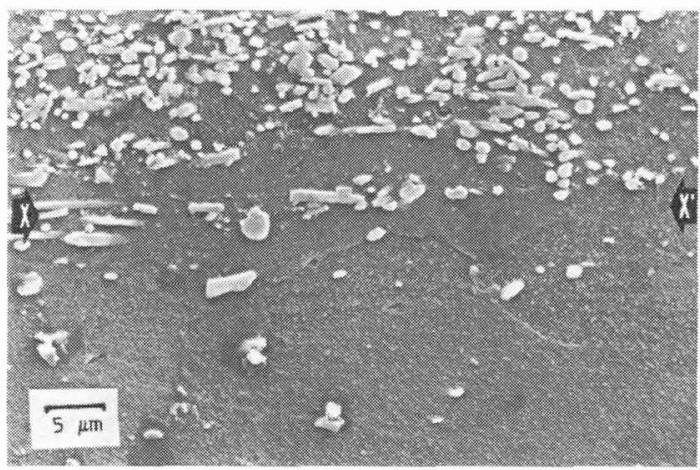

Fig. 4. Detail of recrystallization in SHT DRA/8090 joint $\left(\mathrm{X}-\mathrm{X}^{\prime}\right)$.

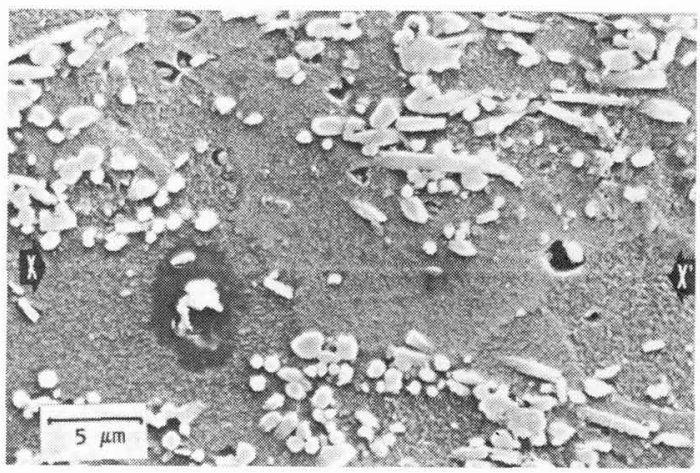

Fig. 5. Detail of recrystallization in an interlayer elimination zone (X-X').

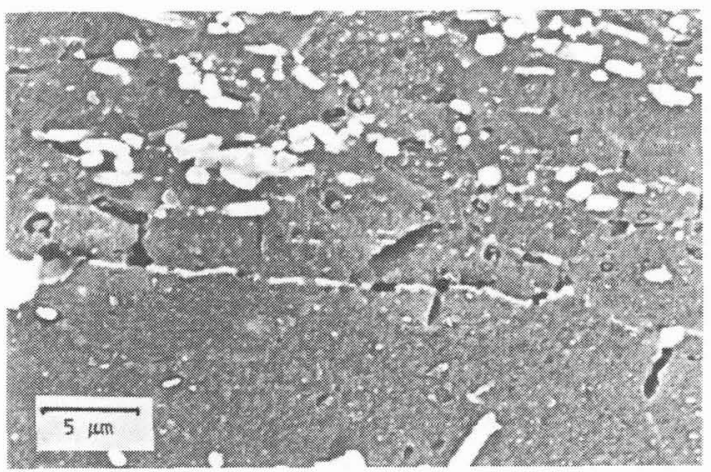

Fig. 6. DRA composite joint with 8090 interlayer $\left(500^{\circ} \mathrm{C}, 3 \mathrm{MPa}\right)$.

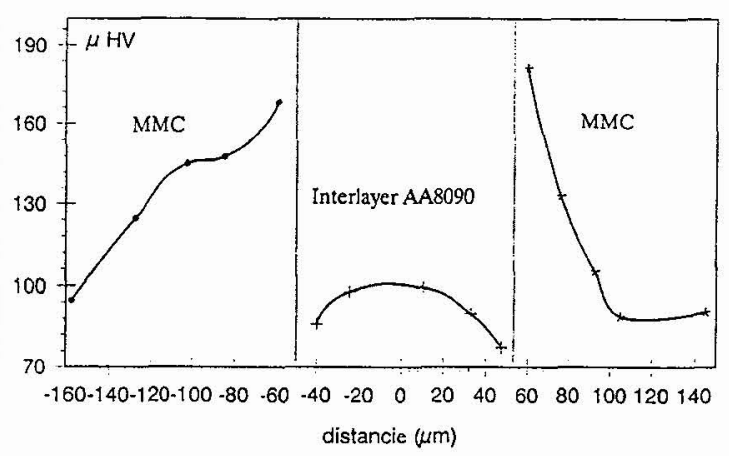

Fig. 7. Microhardness profile in a DRA composite/AA8090 interface.

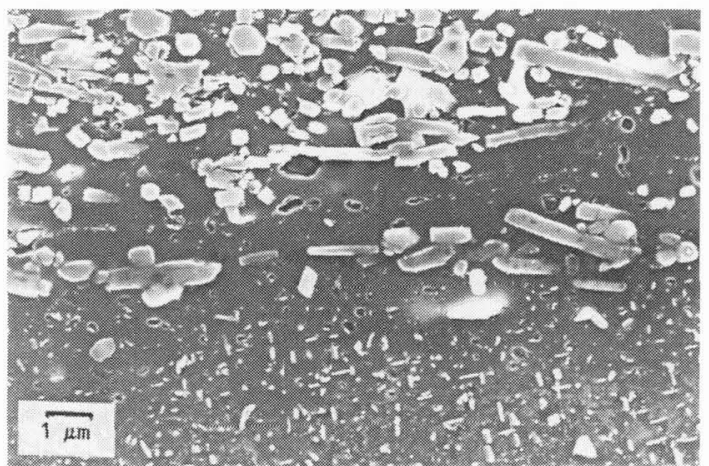

Fig. 8. Detail of interface oxidation in a DRA composite/ 8090 joint $\left(470{ }^{\circ} \mathrm{C}, 6 \mathrm{MPa}\right)$. 


\section{2. $2124 \mathrm{SiC}_{p}$ MMC/SUPRAL 100 diffusion joints.}

Unlike joints bonded with Al-Li interlayers, the reduction in thickness of the SUPRAL foil when it is used as interlayer, was always homogeneous, even when high bulk deformation was induced in the bond pieces (Fig. 9). Microstructural studies of specimens bonded at $500{ }^{\circ} \mathrm{C}, 6 \mathrm{MPa}$ and 60 min showed the achievement of high quality joints free of residual porosity and with an important precipitation of richcopper phases in the interlayer and in the composite matrix (Fig. 10).

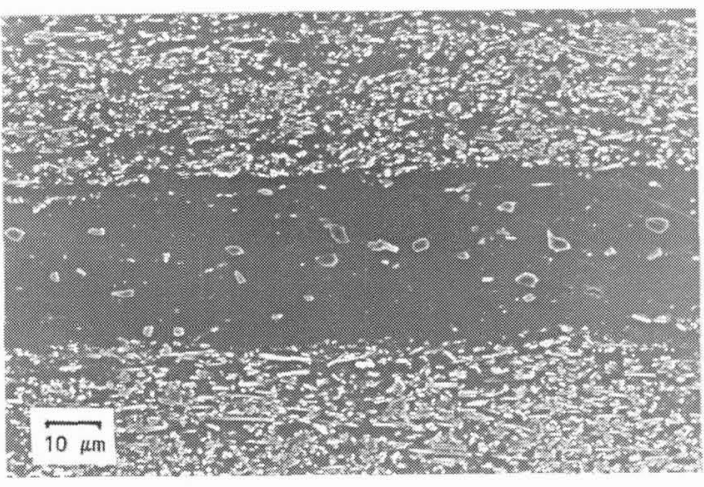

Fig. 9. DRA composite joint with SUPRAL 100 interlayer $\left(470^{\circ} \mathrm{C}, 6 \mathrm{MPa}\right)$.

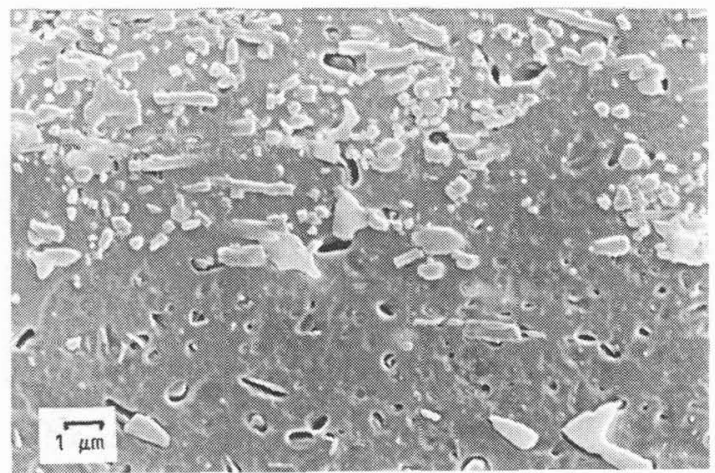

Fig. 10. Detail of DRA/Supral interface with richcopper precipitates.

Solution heat treatment applied $\left(500^{\circ} \mathrm{C}-4 \mathrm{~h}\right.$ and quenching) did not produce the complete solubilitation of rich-Cu phase, although recrystallization and grain growth across the bond interface was again observed (Fig. 11). Some insolated precipitates appeared in the bond interface.

When the bonding pressure was decreased $(3 \mathrm{MPa})$ to reduce the bulk deformation in the pieces, the proportion of rich-copper precipitated formed in the bond interfaces increased. These phases formed, in some zones, an almost continuous layer. In spite of it, interfaces keep a high continuity degree without porosity (Fig. 12).

Copper concentration profiles obtained by quantitative microanalysis across the bond interface show the copper enrichment in the composite matrix close to the bond interface. However, copper diffusion is very limited, in spite of the long bonding time applied, followed by the solution heat treatment ( 2 hours) (Fig. $13)$.

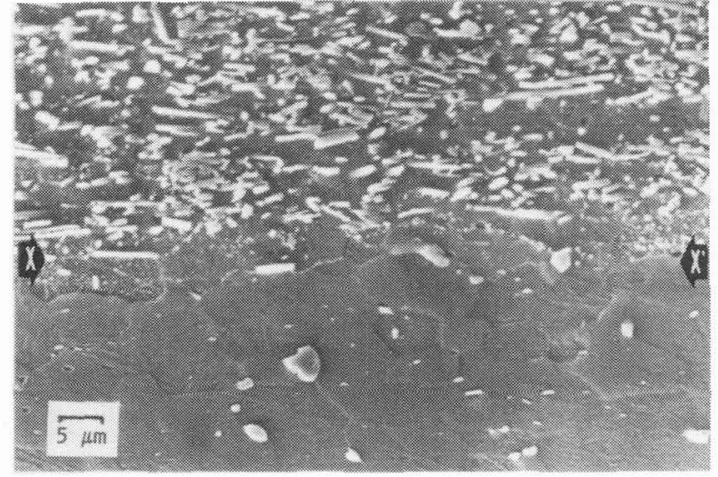

Fig. 11. Interface recrystallization in a DRA composite/Supral joint (X-X')

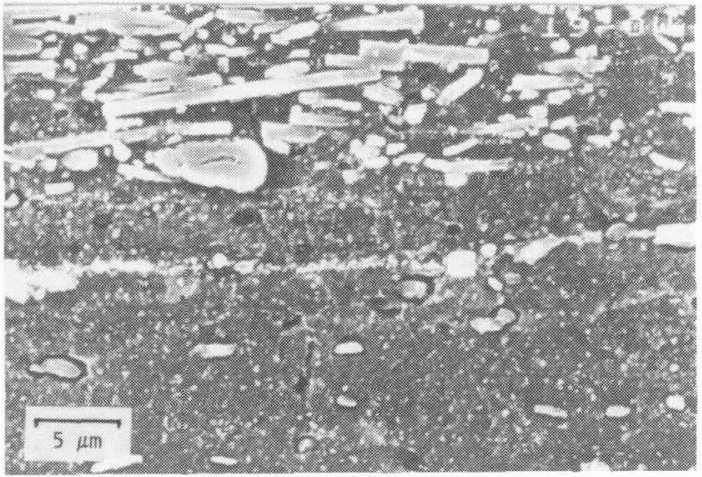

Fig. 12. Interface precipitation of rich-copper phases. 


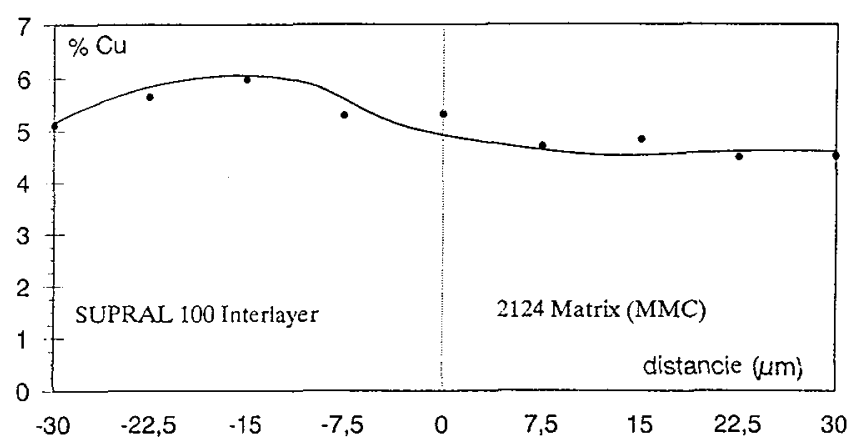

Fig. 13. Copper concentration profile in a DRA/Supral interface.

\section{DISCUSSION.}

The precipitation of rich-Cu phase inside the AA8090 interlayer and the increase of microhardness in the MMC close to the bond interface, only can be explain by interdiffusion phenomena of $\mathrm{Cu}$ and $\mathrm{Li}$. The enrichment of DRA composite in lithium favours the strengthening of 2124 matrix (7) and improves the $\mathrm{SiC} /$ matrix bond as has shown Webster (8).

The study carried out allows to deduce that Li plays an important role in the obtention of high quality joints in DRA composites. It is due to the high activity of $\mathrm{Li}$ which favours the disruption of the alumina film by reaction and formation of less hard and insoluble oxides $\left(\mathrm{LiO}_{2}, \mathrm{LiAlO}_{2}, \mathrm{LiAl}_{5} \mathrm{O}_{8}\right)(9)$.

Diffusion bonding with SUPRAL interlayer shows less evidences of interdiffusion, although a light copper enrichment in the aluminium composite matrix has been detected by EDS. Although bond lines were free of residual porosity, formation of interfacial precipitates has been observed, specially when bonding pressure was reduced. The presence of these phases could condition the final joint strength.

\section{REFERENCES.}

[1] BHAGAT, R.B. "Metal Matrix Composites: Processing and Interfaces". Boston Academic Press. $1991,43-82$.

[2] SCHUSTER, D.M., SKIBO, M.D., HOOVER, W.R. Light Metal Age, (2), 1989, 15-19.

[3] ENJO, T., et al. Trans. JWRI. 16, (2), 1987, 57-64.

[4] PILliNG, J. Proc. Conf. "Superplasticity and Superplastic Forming" TMS. 1988, 475.

[5] HARVEY, J., PARTRIDGE, P.G., SNOOKE, C.L. J. Mater. Sci. 20, 1985. 1009-1014.

[6] PARTRIDGE, P.G., SHEPPERD, M., DUNFORD, D.V. J. Mater. Sci. 26, 1991, 4953-4960.

[7] STARKE, E.A., QUIST, W.E. AGARD Lectures Series on Light Alloys. N. 174, 1990, Chapt. 3.

[8] WEBSTER, D. Metall. Trans. 13A, 1982, 1511.

[9] FOX, S., FLOWER, H.M., McDARMAID, D.S., Proc. Conf. "Aluminium-Lithium III". Institute of Metals. 1986, 263-272. 